\title{
Histórias de Sucesso de Profissionais da Saúde no Tratamento dos Transtornos Alimentares
}

Successful Stories of Health Professionals in Treating Eating Disorders

Historias de Éxito de los Profesionales de la Salud en el Tratamiento de los Trastornos Alimentarios

Laura Vilela e Souza \& Manoel Antônio dos Santos

Universidade de São Paulo

http://dx.doi.org/10.1590/1982-370300132013 
Resumo: O objetivo deste artigo é descrever as histórias de sucesso de profissionais de saúde no atendimento de pessoas diagnosticadas com transtornos alimentares, entendendo que essas narrativas criam contraponto aos sentidos mais amplamente propagados na literatura da área que qualificam negativamente esse relacionamento. Participaram seis profissionais de um serviço de assistência ambulatorial em anorexia e bulimia de um hospital-escola. As entrevistas abertas foram analisadas a partir do discurso construcionista social. Os sentidos realçados abordam a ressignificação do paciente considerado difícil, importância do foco na relação profissional-paciente e não nos sintomas dos transtornos, aprendizado do profissional com o paciente, proximidade afetiva nessa relação, busca de alternativas para o embate de verdades entre profissional e paciente, e a psicoterapia para o profissional como abertura para autoreflexividade no atendimento ao paciente. Esses sentidos convidam à transformação do que vai ser considerado melhora e como o profissional participa do seu alcance.

Palavras-chave: Sucesso profissional. Construcionismo social. Anorexia Nervosa. Bulimia.

Abstract: This article describes success stories of health professionals caring for people diagnosed with eating disorders, revealing that these narratives create a counterpoint to the widely propagated opinions in scientific literature that qualifies this association in negative terms. Six members of the ambulatory healthcare staff of a university hospital who specialized in anorexia nervosa and bulimia were interviewed. The open interviews were then studied using social constructionist discourse analysis. The analysis revealed the following factors: (i) redefining the patients was considered to be difficult, (ii) focusing on the professional-patient relationship and not on the symptoms of the disorders was important, (iii) the professional learning from the patient; (iv) the emotional closeness in this relationship; (v) the search for alternatives to the fight of truths between professional and patient; (vi) and psychotherapy for the professional provide opportunities for reflection on patient care. These factors clarify what is considered health improvement and how the professional participates in this.

Keywords: Occupational success. Social constructionism. Anorexia Nervosa. Bulimia.

Resumen: El objetivo es describir las historias de éxito de los profesionales de la salud en el cuidado de las personas diagnosticadas con trastornos de la alimentación, entendiendo que estas narraciones crean un contrapunto de los sentidos más ampliamente propagados en la literatura que califica esta relación como negativa. Seis profesionales de un servicio de atención ambulatoria de la anorexia y la bulimia, en un hospital universitário, participaron del estudio. Las entrevistas abiertas fueron analizadas a partir del discurso construccionista social. El análisis puso de relieve los sentidos de construcción de los pacientes difíciles, la importancia de centrarse en la relación profesional-paciente en lugar de centrarse en los síntomas de los trastornos, el aprendizaje del profesional con el paciente, la cercanía emocional en esta relación, la búsqueda de alternativas al conflicto de verdades entre profesional y paciente, y la psicoterapia del profesional como posibilidad de autoreflexividad en la atención al paciente. Estos sentidos invitan a la transformación con el objeto de mejorar y mayor alcance profesional.

Palabras clave: Exito profesional. Construcion Social. Anorexia Nerviosa. Bulimia. 


\section{Introdução}

Considerando-se o status atual dos estudos sobre a efetividade das diferentes modalidades de assistência em transtornos alimentares (TA), a aposta tem sido nos tratamentos ambulatoriais como alternativa à internação hospitalar para a promoção de saúde às pessoas diagnosticadas com anorexia nervosa (AN) e bulimia nervosa (BN) (Berkman, Lohr \& Bulik, 2007). Ainda que adolescentes e adultos diagnosticados com AN e BN obtenham melhora significativa com tratamento ambulatorial, muitos desafios se apresentam, especialmente com a alta taxa de abandono de pacientes do tratamento (Collin, Power, Karatzias, Grierson \& Yellowlees, 2010) e taxa de proximadamente 20 a $30 \%$ das pessoas atendidas que não respondem bem ao tratamento (National Health Service, 2010). Alguns autores creditam esses fatos às características de personalidade dos pacientes com TA, que apresentariam resistência à aceitação do diagnóstico (Konstantakopoulos, Tchanturia, Surguladze \& Davi, 2011). Todavia, outros discursos alternativos podem ser explorados no lugar desse da culpabilização do paciente pelo mau êxito do tratamento.

Épossível, em um caminho reflexivo alternativo, questionar em que medida as construções sociais sobre TA dos profissionais da saúde circunscrevem possibilidades de cuidados que podem cristalizar certas formas de atenção em saúde consideradas inadequadas pelos pacientes. Walker e Lloyd (2011) questionaram pacientes de um serviço de assistência em TA sobre o que um bom tratamento deveria contemplar. Os participantes deram ênfase ao relacionamento com o profissional como elemento para melhora e adesão aos atendimentos, mencionando a importância de se estabelecer um vínculo de confiança com o profissional, de uma relação próxima e de não se sentirem julgados. Em outro estudo, aceitação, atenção, respeito, empatia, interesse, honestidade e escuta foram apontados por pacientes como essenciais ao cuidado oferecido pelo profissional de saúde (Bakker, Meijel, Beukers, Omnen, Meerwijk et al., 2011).

Os pontos negativos no relacionamento com o profissional mencionados pelos pacientes foram: a percepção de que nem todos os profissionais têm formação adequada e competência técnica para trabalhar com TA e a falta de compartilhamento de informações entre profissionais e familiares (Walker \& Lloyd, 2011). Outro estudo com objetivo semelhante apontou como aspectos negativos o fato de alguns profissionais se mostrarem afetivamente ausentes nos atendimentos e tratarem o paciente como um objeto (Johansson, Skärsäter \& Danielson, 2007).

Estudos que se propuseram a ouvir os profissionais apontam que essa população teme não dar conta do atendimento a pessoas com TA e receiam perder o controle da situação, dado os riscos físicos envolvidos na AN e BN (Johansson et al., 2007). É comum, na literatura da área, prevalecer o discurso de que atender esses pacientes é uma tarefa árdua, complexa e desgastante para o profissional de saúde (Matz \& Frankel, 2005). Portanto, reivindica-se que tais profissionais possam receber treinamento específico, supervisão constante e apoio emocional (Downsa \& Blowb, 2011). Muitos profissionais relatam, segundoWilliams e Leichner (2006), vivenciarem sentimentos negativos no atendimento a esses pacientes, tais como raiva, irritação e incompetência. Sendo assim, esse atendimento é assumido como desafiador (Satir, Thompson-Brenner, Boisseau \& Crisafulli, 2009). Todos esses aspectos contribuem para a construção de um cenário no qual se valoriza a qualidade do relacionamento profissional-paciente para o alcance da saúde (Federici \& Kaplan, 2008; Johansson et al., 2007; Tierney, 2008). Esse relacionamento, ao mesmo tempo, apresenta-se 
permeado por desafios e temores (Downsa \& Blowb, 2011). No exame da literatura da área, pode-se constatar a escassez de estudos que permitam conhecer de que forma os profissionais de saúde compreendem o que é melhora e como ela pode ser alcançada (Walker \& Lloyd, 2001). Ao se considerar esses impasses no discurso construcionista social, é possível pensar a produção científica como ferramenta de promoção de transformações sociais (McNamee \& Hosking, 2012). Nessa perspectiva, o modo como falamos sobre o relacionamento profissional-paciente é entendido como construção social contextualizada histórica e culturalmente. Tomado como objeto de estudo, o relacionamento profissional-paciente pode ser investigado a partir do convite para a exploração de seus aspectos apreciativos, acreditando que tal enfoque de pesquisa possa gerar recursos para uma situação tomada, muitas vezes, como dilemática (Souza, McNamee \& Santos, 2010). A partir desses pressupostos, a proposta não é ignorar as narrativas possíveis sobre tensões e conflitos vividos no cerne desse relacionamento, mas entender esse objeto e suas descrições como possibilidades discursivas e não como representação de como as coisas são em termos absolutos e essenciais.

Este estudo tem por objetivo descrever histórias de sucesso de profissionais de saúde no atendimento de pessoas diagnosticadas com TA, entendendo que essas narrativas podem criar um contraponto aos sentidos mais amplamente propagados sobre o relacionamento profissional-paciente, resgatando aquilo que é valioso e apreciado nesse relacionamento. Sucesso, neste caso, entendido como os vários sentidos construídos sobre a superação de sintomas ou a cura de doenças, com base nos comentários produzidos na interação com cada profissional envolvido no tratamento dos TA.

\section{Método}

Foram entrevistados seis profissionais de um serviço de assistência ambulatorial em AN e BN de um hospital-escola, sendo: um médico nutrólogo, uma médica psiquiatra, duas nutricionistas e duas psicólogas. A entrevistadora participava da equipe profissional na época da realização das entrevistas, fato que deve ser levado em conta como importante elemento na produção de sentidos nas entrevistas. $\mathrm{O}$ ambulatório funcionava uma vez por semana, seguindo uma programação de consultas individuais com médicos, nutricionistas e psicólogos, psicoterapia individual, grupo de apoio psicológico para pacientes, grupo multifamiliar e grupo de orientação clínico-nutricional para os acompanhantes. O intervalo de retorno dos pacientes no serviço era variável, definido caso a caso. Os pacientes atendidos tinham em média três anos de tratamento. A idade média dos pacientes era de 23 anos. Todos os profissionais, à exceção do médico coordenador do serviço, atuavam no serviço de forma voluntária.

Foi utilizada a modalidade de entrevistas por pautas, que se guia por pontos de interesses previamente estipulados de acordo com os objetivos da pesquisa (Gil, 2008). As histórias de sucesso dos profissionais no atendimento às pacientes foi uma das pautas exploradas no decorrer das entrevistas. As entrevistas foram individuais e audiogravadas mediante autorização dos participantes. Posteriormente, foram transcritas na íntegra e literalmente. Considerando-se os objetivos deste artigo, procedeceu-se um recorte do material, de modo que a análise privilegiou o momento das entrevistadas correspondente à pauta das histórias de sucesso vivenciadas pelos profissionais no atendimento aos pacientes. Essa estratégia de investigação visa a identificar os recursos que os profissionais utilizam para lidarem com os desafios e impasses gerados por narrativas saturadas do problema. 
Os momentos recortados foram analisados a partir do discurso construcionista social, especialmente com o realce dos sentidos coproduzidos na conversação mantida com a entrevistadora sobre o que caracteriza sucesso no tratamento e como o relacionamento profissional-paciente participa de seu alcance. Também foram explorados os discursos sociais que sustentam esses sentidos e quais jogos de posicionamentos eles convidam. Nesse campo, entende-se discurso como o "uso institucionalizado da linguagem" (Spink, 2004, p. 40). Posicionamento é a "construção discursiva de histórias pessoais que fazem as ações das pessoas inteligíveis e relativamente determinadas como atos sociais e dentro das quais os membros da conversa têm posições específicas" (Van Langenhove \& Harré, 1999, p. 16). O discurso construcionista social entende os resultados de pesquisa como coconstruções nas quais o pesquisador participa. Portanto, a análise tecida no presente estudo não pode prescindir da consideração do lugar ocupado pela entrevistadora na relação com os participantes. Assim, a análise dos jogos de posicionamento coloca em evidência o processo dinâmico a partir do qual se posiciona o outro, ao mesmo tempo em que se é posicionado.

O projeto foi aprovado pelo Comitê de Ética em Pesquisa com seres humanos da instituição hospitalar na qual o estudo foi realizado (Protocolo $n^{\circ}$ 7310/2007). Os participantes formalizaram sua anuência com a assinatura do Termo de Consentimento Livre e Esclarecido. Os nomes dos participantes, bem como dos profissionais e pacientes mencionados durante as entrevistas, foram substituídos por pseudônimos a fim de preservar o anonimato.

\section{Resultados}

Solicitou-se a cada entrevistado que procurasse recordar as histórias de sucesso no tratamento que foram mais significativas ou marcantes em sua trajetória profissional. Moema, psicóloga, respondeu:

\begin{abstract}
Moema: Tenho várias histórias que me marcaram. [...] A Vitória, que eu acompanhei na enfermaria e que eu pude ver desde os delírios, assim, de: "Segura a minha mão, porque eu tô ficando muito gorda, eu vou inchar". Delírios persecutórios de que: "Todo mundo tá alterando a balança", "Você tá mentindo para mim". De muito ataque. Até hoje que ela chega e diz que tá bem, tá conseguindo sair, né? Então são histórias que me marcaram muito. [...] Essas pacientes que ficaram mais próximas e que são pacientes mais difíceis, são pacientes que eu tenho histórias bonitas, assim. Porque, é... são pacientes que me procuram, e isso é algo que eu acho que eu conquistei e é algo que eu valorizo muito.
\end{abstract}

Na conversa com Moema podemos ressaltar alguns sentidos co-construídos com a entrevistadora sobre sucesso no relacionamento profissional-paciente: a possibilidade de acompanhar o paciente desde os momentos difíceis até a obtenção de sua melhora (eu pude ver desde os delírios / até hoje que ela chega e diz que tá bem, tá conseguindo sair) e a conquista da proximidade com as pacientes difíceis (que ficaram mais próximas / são pacientes que me procuram, e isso é algo que eu valorizo muito).

Carla, nutricionista, contou que a história que mais a marcou foi a de Marcos, paciente que ela acompanhou do início de seu tratamento até o momento de sua alta. A entrevistadora perguntou o que teria favorecido esse sucesso:

Clara: E eu aprendi com ele, né? Eu acho que eu tava no meu começo, era tudo muito novo, para mim, eu estudava muito, eu ia muito atrás, não fazia, é... terapia na época ainda. É... Fazia só grupo de estudo, que era uma coisa muito básica, na época. Mas eu aprendi 
com ele, sabe? Na época éramos só nós e as residentes, que você sabe que, assim, tão entrando lá também como eu, meio perdidas. Mas existia muito carinho, eu acho, naquilo que eu tava fazendo, e o paciente, aquilo que eu te falei, ele percebe, quando você tá se doando, quando você faz o que você gosta, quando você se dedica. E aí eu acho que teve uma troca entre a gente ali, mesmo, né? Em momentos muito difíceis de resistências, de tentativa de suicídio, de dificuldades, a gente foi evoluindo juntos.

Nesse fragmento de entrevista podemos destacar, como sentidos co-construídos para o sucesso no tratamento: o fato de ser uma novidade para a profissional tratar de pacientes com o diagnóstico de TA (eu tava no meu começo, era tudo muito novo para mim), o investimento em estudos sobre esses quadros (eu estudava muito, eu ia muito atrás), a possibilidade de aprender com o paciente (Mas eu aprendi com ele, sabe?), a dedicação afetuosa ao paciente (existia muito carinho, eu acho, naquilo que eu tava fazendo), a relação de troca com o paciente nos momentos difíceis (teve uma troca entre a gente ali, mesmo, né? Em momentos muito difíceis de resistências, de tentativa de suicídio, de dificuldades) e a evolução que profissional e paciente trilharam juntos (a gente foi evoluindo juntos).

Tiago, médico psiquiatra, selecionou sua história de sucesso a partir do atendimento de Tatiana. As consultas de Tatiana eram realizadas por Tiago e Clara conjuntamente, na tentativa de incrementar as possibilidades de diálogo e troca entre os profissionais da equipe:

Tiago: Teve um dia, uma consulta que demorou e foi eu e a Clara junto, demorou quase duas horas, uma hora e meia, né? Foi dureza, com ela [Tatiana] chorando bastante. Foi uma consulta pesadíssima. Dessa consulta em diante, a Tatiana mudou o comportamento, claramente. Essa consulta, eu lembro, que a gente puxando pra um lado, ela puxando pro outro: "Não Tatiana, mas o certo é isso". Assim, tô resumindo. A gente não falou com essas palavras, mas: "O certo é isso e você faz isso", "O certo é isso". E ela falava: "Não, o certo é isso", "O certo é isso", "O certo é isso". E ficava naquela coisa até que eu lembro que eu comecei a pensar numa entrevista motivacional que eu trabalhei com o Dr. Juca aqui no hospital, que é uma técnica que um americano criou. Por mais que a Tatiana tenha as dificuldades, ela que vai ter que decidir com base na percepção dela de enxergar vantagens ou desvantagens nisso. A partir do momento que eu comecei a puxar isso, virou o jogo. Eu falei: "Tatiana, então, tá, você quer fazer isso, né? Vem cá, vamos analisar juntos então, isso pode ser uma possibilidade, Você quer tomar só água o dia inteiro? Então pode ser uma possibilidade. Eu não concordo, minha posição é clara por causa disso, disso, disso". Aí, quando eu falo: "Disso, disso, disso", eu falo tudo aquilo que eu tava pensando, as razões. [...] Quando eu comecei a jogar isso pra ela, eu acho que ela assustou, sabe? Porque eu acho que ela deu uma quebrada, totalmente, nos últimos 20 minutos mais ou menos, ela quebrou total.

Desse fragmento de entrevista, é possível ressaltar como significativo para o sucesso no relacionamento entre Tiago e Tatiana: a paciente perceber as vantagens e desvantagens de seus comportamentos alimentares por si mesma, e não pelo simples poder de persuasão do profissional (Por mais que a Tatiana tenha as dificuldades, ela que vai ter que decidir com base na percepção dela de enxergar vantagens ou desvantagens nisso); o profissional poder se colocar ao lado e analisar essas vantagens e desvantagens juntamente com a paciente, em vez de apenas lhe ditar o que é certo ou errado (Vem cá, vamos analisar juntos então); abrir espaço na conversa para que a paciente 
expresse abertamente o que está querendo fazer, ainda que o profissional discorde de seu posicionamento (Você quer tomar só água o dia inteiro? Então pode ser uma possibilidade) e garantir que a paciente entenda as razões pelas quais o profissional discorda de seu posicionamento (Eu não concordo, minha posição é clara por causa disso, disso, disso).

Larissa, nutricionista, contou sua história de relacionamento com uma paciente diagnosticada com AN:

Larissa: Eu lembro de uma paciente nossa, que ela ficou, assim, muito resistente ao tratamento. [...] Ela ficou um ano assim, no mesmo peso, sabe? Um peso baixo, um peso assim, de risco, naquela situação assim, de que todo atendimento a gente falava: "E agora?" "Será que precisa internar, será que não", né? Então um conflito muito grande, assim, da equipe em ver até aonde a gente podia ir. E depois de um ano eu acho que ela resolveu se tratar, sabe? Então eu acho que é um pouco disso, a família quer o tratamento, a equipe quer $\mathrm{o}$ tratamento, mas o paciente não quer e ele vai levando, né, ele vai levando o tratamento do jeito que ele quer.

O sentido sobre sucesso no tratamento coconstruído nesse momento da conversa é do paciente ter que tomar a decisão de se cuidar e aceitar o tratamento ( $E$ depois de um ano eu acho que ela resolveu se tratar, sabe?), algo que independe do desejo da equipe de profissionais da saúde ou da família para que aconteça.

Mauro, médico nutrólogo, também resgatou uma história de sucesso:

Mauro: Uma paciente, recentemente, entrou e falou assim: "Olha, hoje eu não trouxe a lição de casa", que era o registro alimentar. E eu vi que eu tava tentando ser professor dela, né? Ela me ensinou bastante coisa.
Entrevistadora: [Risos] O que você acha que te ajudou?

Mauro: [Suspiro] É você entender que você influencia, conversa, explica, mas que existe um entendimento do lado de lá do processo, né? E, claro que ajudou também foi o fato de eu fazer análise [processo terapêutico de abordagem psicanalítica]. Eu acho que é fundamental você se compreender também nesse processo.

Entrevistadora: E o que você acha que a ajudou a poder dizer isso a você?

Mauro: Essa paciente. Ela tava em um processo de análise também.

Nesse fragmento da entrevista podemos resgatar os seguintes sentidos para o sucesso no relacionamento profissional-paciente: a possibilidade de o paciente chamar a atenção do médico para o modo como estão interagindo (e eu vi que eu tava tentando ser professor dela, né?), o que pode promover no profissional uma reflexão crítica sobre essa interação; a disponibilidade do médico em aprender com a paciente (Ela me ensinou bastante coisa); a necessidade de levar em conta o entendimento que a paciente tem da situação e das explicações médicas ( $E$ você entender que você influencia, conversa, explica, mas que existe um entendimento do lado de lá do processo); o fato de o médico receber o suporte de outro profissional em sessões de psicanálise (claro que ajudou também foi o fato de eu fazer análise), de forma a poder se compreender na relação com o paciente (acho que é fundamental você se compreender); e o fato de a paciente também estar em processo psicoterapêutico (Ela tava num processo de análise também), o que propicia conversar com o médico sobre o relacionamento estabelecido pela dupla.

Marta, psicóloga, mencionou uma paciente que atendia na época da entrevista: 
Marta: Tem essa paciente que eu acho que é a que tá me inspirando e me ensinando muito. Acho que a partir do momento que eu comecei - mesmo considerando a importância do atendimento familiar - mas eu comecei a olhar mais pra ela, né? Porque vinham demandas familiares junto, mãe tentando falar na sala. A partir do momento em que eu consegui delimitar que o espaço ali era pra ela, eu percebi que veio vindo uma construção de sonhos. Que ela chegou pra mim sem sonhar, sem ter a capacidade de imaginar coisas, era tudo muito concreto, não podia receber afeto, não podia receber nada, nem alimento. A partir do momento em que eu comecei a sonhar por ela e depois contar que ela podia fazer isso também, eu acho que é uma experiência que eu tô vendo resultados, né? Ela tá conseguindo adquirir peso aos pouquinhos. Tá conseguindo entender que ela tem um mundo emocional que tá sofrendo.

Os sentidos que Marta co-construiu durante a entrevista sobre o que seria uma história de sucesso na relação com a paciente que a estava inspirando foram: focar no atendimento individual da paciente, ainda que sem desconsiderar a importância de toda a família ser assistida (mesmo considerando a importância do atendimento familiar - mas eu comecei a olhar mais pra ela), delimitar o espaço do atendimento psicoterápico para as demandas da paciente, e não dos demais familiares (Porque vinham demandas familiares junto, mãe tentando falar na sala. A partir do momento que eu consegui delimitar que $o$ espaço ali era pra ela, eu percebi que veio vindo uma construção de sonhos), incentivar a paciente a sonhar com seu futuro (A partir do momento que eu comecei a sonhar por ela e depois contar que ela podia fazer isso também, eu acho que é uma experiência que eu tô vendo resultados), ao mesmo tempo em que pode reconhecer o sofrimento atual (Tá conseguindo entender que ela tem um mundo emocional que tá sofrendo).

\section{Discussão}

$\mathrm{Na}$ análise dos fragmentos de entrevista com os profissionais foi possível destacar algumas narrativas sobre sucesso no tratamento, levando-se em conta a importância da qualidade da relação profissional-paciente. São elas: o foco no processo relacional e a proximidade afetiva como estratégias para lidar com a gravidade dos sintomas dos TA; a possibilidade de aprender com o paciente para lidar com a falta de experiência no atendimento a esses transtornos; a busca de formas alternativas de interação com o paciente que não caiam em jogos de posicionamentos de disputa de verdades no campo da saúde; a auto-reflexividade, via apoio emocional oferecido ao profissional, como forma de avaliação da relação com o paciente e a separação entre a demanda da família e do paciente.

Os sentidos sobre melhora ressaltados na entrevista com Moema fazem eco com a demanda dos pacientes que, de acordo com a literatura da área, solicitam uma relação próxima e de confiança com o profissional (Walker \& Lloyd, 2011). Ao contrário dos relatos frequentes de que a gravidade dos sintomas gera no profissional uma sensação de incompetência, desapontamento e frustração com os resultados do tratamento (Satir et al., 2009), Moema apontou justamente o atendimento às pacientes mais "difíceis" como aquilo que qualificava seu papel profissional. Podemos pensar que, quando o foco do tratamento é o ganho de peso ou a remissão dos sintomas do TA, o acompanhamento de um paciente com delírios somáticos e outros sintomas graves pode ser frustrante. Todavia, o relato de Moema conta da possibilidade de ter como objetivo fortalecer a parceria com o paciente durante o tratamento, com foco naquilo que vai ser conquistado nessa relação. 
O relato de Clara, por sua vez, faz contraponto aos discursos mais tradicionais e cristalizados em saúde, que definem a hierarquia entre profissional e paciente a partir do maior conhecimento que o primeiro dispõe em relação ao que está sendo definido como foco de cuidado (Souza \& Scorsolini-Comin, 2011). A partir desse discurso, Clara teria dificuldade em assumir um lugar de aprendiz no relacionamento com Marcos. Interessante notar que justamente aquilo que, na literatura, é mencionado como um aspecto negativo, ou seja, a falta de treinamento específico do profissional no tratamento dos TA (Downsa \& Blowb, 2011), foi o que permitiu que Clara e Marcos pudessem manter um bom relacionamento durante o tratamento. A falta de prática no atendimento de pacientes com TA permitiu que Clara-profissional pudesse aprender com Marcos-paciente, o que pode ter feito com que ele se sentisse ouvido e pudesse reconhecer em Clara um interesse genuíno e honestidade de propósitos (o paciente, aquilo que eu te falei ele percebe, quando você tá se doando, quando você faz o que você gosta, quando vocêse dedica), características almejadas pelos pacientes (Bakker et al., 2011).

Outro contraponto com um discurso que também é dominante no campo das práticas de saúde pode ser ressaltado na entrevista de Clara. $\mathrm{Na}$ hierarquia construída entre profisssional e paciente, um relacionamento afetivamente neutro é requerido por certo discurso em saúde que defende que um profissional emocionalmente afetado pela situação do paciente pode perder sua capacidade de julgamento objetivo em relação ao seu atendimento (Brusset, 2003). Clara utilizou justamente de seu afeto, do "carinho", conforme declarou, como forma de lidar com sua falta de conhecimento científico sobre oTA. O que não a impediu de valorizar ou de investir em estudos formais, que de forma mais direta respondem a essa posição de saber do profissional.
O aprender com o paciente, referido por Clara em sua entrevista, é um dos meios pelos quais o profissional de saúde pode se colocar em uma posição mais horizontal e igualitária junto ao paciente. Johansson et al. (2007), pesquisadores da área dos TA, mostram em seu estudo o êxito obtido por alguns serviços de assistência em AN e BN que tomaram os pacientes como fonte de recursos de melhora. Nesses serviços, os pacientes ficam lado a lado com o profissional de saúde e ocupam o papel de fornecerem apoio a outros pacientes, como estratégias de melhora. Esses pesquisadores ressaltam os malefícios de uma postura paternalista do profissional de saúde, que se coloca como aquele que sabe o que é melhor para o paciente.

A "quebrada total" que Tiago mencionou em sua entrevista parece ter sido a ruptura de uma dinâmica relacional que havia se instaurado na interação com Tatiana, na qual os profissionais travavam um verdadeiro embate de opiniões. Quando Tiago validou a opinião de Tatiana, ao mesmo tempo em que afirmou que era contrário a ela, ele permitiu que outro jogo de posicionamento se estabelecesse entre eles. A saber, não era mais o profissional que considerava que sabia o que era melhor para o paciente, mas duas pessoas com diferentes modos de pensar sobre a questão e que se julgavam corretos a partir de lógicas distintas.

Essa possibillidade de achar uma alternativa ao embate entre profissional e paciente parece ir na direção do que é apontado por Bakker et al. (2011) de que um bom êxito no tratamento, do ponto de vista do paciente, depende da aceitação do profissional sobre o modo como ele vivencia sua relação com a alimentação. $A$ história resgatada por Tiago convida a pensar que o paciente não precisa ser julgado (Walker \& Lloyd, 2011) para que o profissional possa dizer o que considera saudável ou não. Frente a um grave quadro de desnutrição, podemos 
pensar na dificuldade do médico em ouvir a recusa radical de Tatiana em se alimentar. A partir desse lugar, podemos compreender os relatos de outros profissionais sobre suas sensações de raiva, irritação e incompetência vivenciadas durante o atendimento a esses pacientes considerados intransigentes, que não se deixam dobrar pela autoridade médica (Satir et al., 2009). Porém, se for possível perceber, a conversa não como uma disputa de verdades, mas como a constatação de diferentes modos de se pensar e conceber um mesmo objeto, o tratamento pode ser um espaço de co-responsabilização pela melhora, envolvendo profissional e paciente em um projeto compartilhado.

Estudos indicam que a motivação do paciente para mudança é um dos aspectos fundamentais para a conquista de bons resultados no tratamento (Federici \& Kaplan, 2008). Esse sentido pode convidar à manutenção da sensação de impotência do profissional (Walker \& Lloyd, 2011), quando está diante de pessoas consideradas refratárias às prescrições do tratamento. Todavia, visto como uma forma de aceitação e respeito ao momento particular do paciente (Bakker et al., 2011), pode ter uma dimensão positiva, como no exemplo dado por Larissa. Ao considerar que a literatura ressalta a $\mathrm{AN}$ e BN como quadros crônicos desafiadores quanto à obtenção da adesão ao tratamento (Johansson et al., 2007), poder entender que o sucesso da terapêutica instituída não é algo que depende apenas do esforço do profissional pode resultar em alívio.

Como foi possível discutir a partir da entrevista com Larissa, o foco exclusivo na melhora dos sintomas pode posicionar o paciente como "rebelde" intratável, "resistente" ao tratamento, e o profissional como impotente na oferta de ajuda. Uma controvérsia em relação ao objetivo do tratamento refere-se à crítica ao foco exclusivo que alguns serviços colocam nos sintomas doTA, entendendo que a simples recuperação de peso ou o decréscimo dos comportamentos alimentares considerados inadequados seriam, automaticamente, sinônimos de melhora. Abre-se a discussão sobre o que está sendo considerada recuperação e de que forma a assistência em saúde pode dar conta de aspectos mais amplos que incluam o bem-estar psicológico do paciente e a construção de uma rede de apoio social para além do âmbito do tratamento (Downsa \& Blowb, 2011).

O discurso biomédico do diagnóstico do TA, que define $\mathrm{AN}$ e BN como entidades nosológicas que se dispõem ao longo de um contínuo, pode reificar um estado psicopatológico nas pessoas diagnosticadas. Quando o discurso do diagnóstico é colocado como a verdade suprema sobre o que estaria acontecendo com o paciente, qualquer outra descrição é posta de lado ou vista como errônea. Uma proposta de tratamento que seja fundada na ideia essencialista do funcionamento psicopatológico pode impedir um paciente que não aceite o diagnóstico de receber ajuda. Nesse sentido, propostas atuais defendem tratamentos personalizados, de acordo com a necessidade de cada pessoa atendida (Downsa \& Blowb, 2011), questionando-se o foco exclusivo do tratamento na remissão dos sintomas dos TA (Bakker et al., 2011).

Poder olhar para a qualidade da interação empreendida com o paciente, como fez Mauro, vai ao encontro do pedido dos pacientes de não serem tratados como objeto (Johansson et al., 2007), mas serem ouvidos e considerados como protagonistas de seu tratamento (Bakker et al., 2011). Assim como o fazem alguns pesquisadores contemporâneos da área (Downsa \& Blowb, 2011), Mauro falou da importância do apoio emocional recebido pelo profissional para qualificar o atendimento oferecido aos pacientes com TA. Mas esse apoio não foi construído no relato de Mauro como um requisito necessário devido 
à "resistência" do paciente ao tratamento, ou pelo fato de o paciente ter uma "personalidade difícil", o que traria sobrecarga emocional ao profissional. Diferentemente disso, nesse momento da entrevista o apoio emocional via psicoterapia foi construído como aquilo que permitiu ao profissional escutar o paciente - e, simultaneamente, a si próprio - e desenvolver empatia por seu modo peculiar de entender o transtorno.

A história relatada por Mauro chama a atenção para a possibilidade de uma postura de auto-reflexividade do profissional em relação a como está realizando seus atendimentos. Lester (2007) critica as imposições ideológicas dos profissionais aos pacientes a partir da prescrição de uma série de atividades nas quais eles têm que participar compulsoriamente. Dentre essas imposições estaria o convencimento dos pacientes acerca do valor dessas intervenções, da existência do acometimento por um "transtorno" e da necessidade de seu tratamento. Pacientes que desistiram do tratamento declararam aos profissionais que não se percebiam com TA, de modo que o tratamento não parecia fazer sentido. Muitos falaram de como não estavam satisfeitos com o tratamento, com seu objetivo de recuperação de peso e com as intervenções psicológicas. Alguns relataram que não se sentiam preparados para a vida pós-tratamento (Federici \& Kaplan, 2008). Considerar que o sucesso no tratamento é sinônimo do paciente admitir que tem uma "doença" pode contribuir para manter os problemas atualmente enfrentados nos tratamentos de AN por meio de internação hospitalar compulsória. Sabe-se que há pacientes que recebem alta quando alcançam o peso ideal e que, ao voltarem para casa, emagrecem novamente (Downsa \& Blowb, 2011).

Historicamente, a inclusão da família no tratamento dos TA foi, em um primeiro momento, defendida como necessária pelo fato da família também estar adoecida ou até por se suspeitar de que ela seria o locus de origem dos sintomas do paciente (Souza \& Santos, 2010). Atualmente, a proposta mais aceita é de que a família também sofre com a sobrecarga imposta pelo convívio com oTA e que necessita de apoio multiprofissional, com modalidades de atendimentos coordenados para família e paciente (American Psychiatric Association, 2006; Scorsolini-Comin, Souza \& Santos, 2010; Souza \& Santos, 2006, 2007, 2009). A participante Marta mencionou como o foco nas demandas familiares pode tirar a atenção do paciente, impedindo muitas vezes de escutá-lo em suas necessidades.

Um aspecto valorizado como positivo nesse relacionamento foi a possibilidade de Marta sonhar por sua paciente, em um movimento de envolvimento que se encontra embasado pela teoria e técnica psicoterápicas. Todavia, mais do que o simples cumprimento de um preceito técnico, o formato do atendimento, individualizado parece ter permitido, segundo a profissional, que o cuidado emocional à paciente pudesse acontecer, abrindo espaço para as duas poderem estar juntas e sonharem.

\section{Conclusões}

Quando consideramos a dificuldade frequentemente relatada por profissionais e pesquisadores dos TA para alcançarem um tratamento eficaz (Federici \& Kaplan, 2008), podemos formular a aposta no relacionamento profissional-paciente como locus de produção de sentidos sobre a melhora. Todavia, sua efetivação no âmbito do tratamento dos TA ainda se constitui em desafio, uma vez que as diretrizes de muitos serviços de assistência em TA defendem a postura firme e de tenacidade do profissional na imposição de regras e atitudes aos pacientes (Bakker et al., 2011). 
As apostas no discurso construcionista social em saúde (Souza \& Scorsolini-Comin, 2011) e nos princípios discursivos em saúde do Sistema Único de Saúde - SUS (Ministério da Saúde, 2009) são marcos inspiradores para a proposta de práticas que tomem o paciente como protagonista, aliando-se ao profissional da saúde na co-construção do tratamento, e para que a qualidade do encontro entre profissional e paciente seja tomada como eixo norteador da busca de excelência na produção de saúde.

O discurso construcionista social em saúde considera o saber do paciente e profissional como válidos a partir de lógicas discursivas distintas (Souza \& Scorsolini-Comin, 2011). Propõe-se, então, a possibilidade dos pacientes serem convidados a participar do delineamento das propostas de atendimento nos serviços de assistência em TA e a viabilidade de profissionais e pacientes buscarem conhecer, de forma curiosa, os sentidos de mundo que sustentam a posição tomada por cada um deles em relação ao tratamento.

A ênfase dada pelo profissional de saúde à maneira como ele se relaciona com o paciente tem sido considerado um instrumento de produção de saúde pelas políticas do SUS, na medida em que favorece o uso da chamada "tecnologia do encontro". Trata-se de um cuidado constante com o "estar com" e "estar perto" do paciente, um foco que não pode ser perdido em nenhum dos níveis de atenção em saúde (Brasil, 2009). O uso desse instrumento e dessa tecnologia oferecem possibilidades, quando consideramos a assistência ambulatorial dos TA, de construção de alternativas ao discurso apregoado na literatura, com sua insistência no déficit em vez de considerar os recursos. Assim, ainda são pregnantes no cenário assistencial sentidos como: a resistência incoercível do paciente, a dificuldade de manter um bom relacionamento profissional com essa população e a sobrecarga emocional advinda dessa interação. O uso da tecnologia do encontro apresenta um modelo de atuação que busca encontrar no próprio relacionamento profissional-paciente os recursos para a manutenção de um bom relacionamento. Com isso, não estamos advogando contra a especialização profissional, mas apostando no potencial das co-construções profissional-paciente como mais um elemento para o alcance daquilo que vai ser considerado por essa dupla como saúde e sucesso no tratamento. 


\section{Laura Vilela e Souza}

Doutora em Psicologia pela Universidade de São Paulo, São Paulo - SP. Brasil. Docente da Universidade de São Paulo, São Paulo - SP. Brasil.

E-mail: laura@ffclrp.usp.br

\section{Manoel Antônio dos Santos}

Doutor em Psicologia pela Universidade de São Paulo, São Paulo - SP. Brasil. Docente da Universidade de São Paulo, São Paulo - SP. Brasil.

E-mail: masantos@ffclrp.usp.br

\section{Endereço para envio de correspondência:}

Faculdade de Filosofia, Ciências e Letras de Ribeirão Preto USP, Departamento de Psicologia e Educação.

Avenida Bandeirantes, 3900, Vila Monte Alegre. CEP: 14040-901. Ribeirão Preto - SP. Brasil.

Agradecimento: Ao Conselho Nacional de Desenvolvimento Científico e Tecnológico

- CNPq - pela Bolsa de Produtividade em Pesquisa concedida ao segundo autor.

Recebido 21/10/2012, Reformulação 10/01/2014, Aprovado 08/04/2015. 


\section{Referências}

American Psychiatric Association. (2006). Practice guideline for the treatment of patients with eating disorders. Recuperado de: http://www.psych.org

Bakker, R., Meijel, B., Beukers, L., Ommen, J., Meerwijk, E., \& Elburg, A. (2011). Recovery of normal body weight in adolescents with anorexia nervosa: The nurses' perspective on effective interventions. Journal of Child and Adolescent Psychiatric Nursing, 24(1), 16-22.

Berkman, N. D., Lohr, K. N., \& Bulik, C. M. (2007). Outcomes of eating disorders: A systematic review of the literature. International Journal of Eating Disorders, 40(4), 293-309.

Brusset, B. (2003). Conclusões terapêuticas. In B. Brusset, C. Couvreur, A. Fine (Ed.), A bulimia (pp. 173-184). São Paulo: Escuta.

Collin, P., Power, K., Karatzias, T., Grierson, D., \& Yellowlees, A. (2010). The effectiveness of, and predictors of response to inpatient treatment of Anorexia Nervosa. European Eating Disorders Review, 18(6), 464-474.

Downsa, K. J., \& Blowb, A. J. (2011). A substantive and methodological review of family-based treatment for eating disorders: The last 25 years of research. Journal of Family Therapy, 34(2), 1-26. doi: 10.1111/j.1467-6427.2011.00566.x

Federici, A., \& Kaplan, A. S. (2008). The patient's account of relapse and recovery in anorexia nervosa: a qualitative study. European Eating Disorders Review, 16(1), 1-10.

Gil, A. C. (2008). Métodos e técnicas de pesquisa social (6a ed.). São Paulo: Atlas.

Johansson, I. M., Skärsäter, I, \& Danielson, E. (2007). Encounters in a locked psychiatric ward environment. Journal of Psychiatric and Mental Health Nursing, 14(4), 366-372.

Konstantakopoulos, G., Tchanturia, K., Surguladze, S. A., \& Davi, A. S. (2011). Insight in eating disorders: clinical and cognitive correlates. Psychological Medicine, 41(9), 1951-1961. doi: $10.1017 /$ S0033291710002539

Lester, R. J. (2007). Critical therapeutics: Cultural politics and clinical reality in two eating disorder treatment centers. Medical
Anthropology Quarterly, 21(4), 369-387. doi: 10.1525/MAQ.2007.21.4.369.

Matz, J., \& Frankel, E. (2005). Attitudes toward disordered eating and weight: Important considerations for therapists and health professionals. Journal of Health at Every Size, 19(1), 19-30.

McNamee, S., \& Hosking, D.M. (2012). Research and social change: A relational constructionist approach. New York, NY: Routledge.

Ministério da Saúde. (2009). O SUS de A a Z: Garantindo saúde nos municípios. Brasília, DC: autor.

National Health Service. (2010). Anorexia nervosa [Online]. NHS Choices. Recuperado de: http://www.nhs.uk/Conditions/Anorexianervosa/Pages/Introduction.aspx

Satir, D. A., Thompson-Brenner, H., Boisseau, C. L., \& Crisafulli, M. A. (2009). Countertransference reactions to adolescents with eating disorders: relationships to clinician and patient factors. International Journal of Eating Disorders, 42(6), 511-521.

Scorsolini-Comin, F., Souza, L. V., \& Santos, M. A. (2010). A construção de si em um grupo de apoio para pessoas com transtornos alimentares. Estudos em Psicologia (Campinas), 27(4), 467-478.

Souza, L. V., \& Santos, M. A. (2006). A família e os transtornos alimentares. Medicina, 39(3), 403-409.

Souza, L. V., \& Santos, M. A. (2007). Anorexia e bulimia: Conversando com as famílias. São Paulo, SP: Vetor.

Souza, L. V., \& Santos, M. A. (2009). A construção social de um grupo multifamiliar no tratamento dos transtornos alimentares. Psicologia: Reflexão e Crítica, 22(3), 317-326.

Souza, L. V., \& Santos, M. A. (2010). A participação da família no tratamento dos transtornos alimentares. Psicologia em Estudo, 15(2), 285-294.

Souza, L. V., \& Scorsolini-Comin, F. (2011). Relações profissionais em Equipes de Saúde: alternativas construcionistas relacionais. Saúde e Transformação Social, 1(3), 37-46. 
Souza, L. V., McNamee, S., \& Santos, M. A. (2010). Avaliação como construção social: Investigação apreciativa. Psicologia e Sociedade, 22(3), 598-607.

Spink, M. J. P. (2004). Linguagem e produção de sentidos no cotidiano. Porto Alegre, RS: EDIPUCRS.

Tierney, S. (2008). The individual within a condition: A qualitative study of young people's reflections on being treated for anorexia nervosa. Journal of the American Psychiatric Nurses Association, 13(6), 368375. doi: 10.1177/1078390307309215
Van Langenhove, L., \& Harré, R. (1999). Introducing positioning theory. In: R. Harré, L. Van Langenhove (Eds.), Positioning theory (pp. 14-31).Oxford: Blackwell.

Walker, S., \& Lloyd, C. (2011). Issues experienced by service users with an eating disorder: A qualitative investigation. International Journal of Therapy and Rehabilitation, 18(10), 542-550.

Williams, M., \& Leichner, P. (2006). More training needed in eating disorders: A time cohort comparison study of Canadian psychiatry residents. Eating Disorders, 14(4), 323-334. 